\title{
OPTIMIZATION OF WIRE EDM PROCESS PARAMETERS FOR MACHINING
}

\section{OF AMCs $\left(413 / B_{4}\right.$ C) USING TAGUCHI TECHNIQUE}

\author{
J. UDAYA PRAKASH ${ }^{1}$, S. JEBAROSE JULIYANA ${ }^{2}$, S. KARTHIK ${ }^{3} \&$ T. V. MOORTHY ${ }^{4}$ \\ 1, 2, 3 Department of Mechanical Engineering, Veltech Dr. RR \& Dr. SR University, Chennai, India \\ ${ }^{4}$ Department of Manufacturing Engineering, College of Engineering, Guindy, Anna University, Chennai, India
}

\begin{abstract}
The effects of the machining parameters in Wire Electrical Discharge Machining (WEDM), by varying pulse on time, pulse off time, gap voltage and wire feed on the machining characteristics of fabricated Aluminium Matrix Composites $\left(A M C-413 / B_{4} C\right)$, using stir casting process were investigated. The experiments were conducted with the $L_{27}$ orthogonal array, based on the Taguchi Technique. Analysis of variance (ANOVA) were done, to find the significance of machining parameters, which affects the quality characteristics of WEDM process and also, to find the relative contribution of machining parameters, in controlling the responses of the WEDM process. The optimal combination levels of machining parameters, for material removal rate and surface roughness were determined. The parameter with the strongest influence on the response is determined by signal to noise $(S / N)$ ratio response analysis. However, as a final step, confirmation experiment has also been conducted with the optimum combination, to predict and verify the improvement of the observed values
\end{abstract}

KEYWORDS : AMCs, WEDM, Taguchi Technique, S/N Ratio \& ANOVA

Received: Oct 04, 2017; Accepted: Oct 25, 2017; Published: Nov 11, 2017; Paper Id.: IJMPERDDEC201725

\section{INTRODUCTION}

Metal Matrix Composites has more demand in modern industrial world [1]. Metal matrix composites has promising application as hi-tech structural and general engineering materials because of their higher specific modulus, strength, thermal stability, and wear resistance. [2]. Al-Si alloys are usually used as the matrix material in Aluminum Matrix Composites. AMCs are used in sporting goods, electronic packaging and automotive industries. They are usually reinforced by $\mathrm{Al}_{2} \mathrm{O}_{3}, \mathrm{SiC}$, carbon, boron carbide and also with recently fly ash. AMCs are very attractive for their isotropic mechanical properties and the cost of the material is cheaper than all other matrix materials. Machining of aluminum matrix composites are very difficult by conventional machining process, namely turning, milling, drilling and sawing etc. due to their extreme abrasive properties [3-5]. Che Chung Wang [6] investigated optimization of the blind-hole drilling of $\mathrm{Al}_{2} \mathrm{O}_{3} / 6061 \mathrm{Al}$ composites, using rotary electro discharging machining, by using Taguchi method. Experimental results confirmed that, the revised copper electrode with an eccentric through-hole had the optimum performance, for machining from various aspects. Sivaprakasam Palani [7], investigated micro wire electrical discharge machining process with multiple performance characteristics, based on the response surface methodology, using AMCs and Al Alloy 2024.

Thus unconventional machining like electric discharge machining (EDM) methods can be effectively used for machining of MMCs. [8-14]. This paper deals with the machinability and optimization of $413 / \mathrm{B}_{4} \mathrm{C}$ composites. The results of the machining such as MRR and surface roughness in response to the input parameters of WEDM 
machine were presented in this paper.

\section{MATERIALS}

Material has been selected based on the properties, cost and application. Since only little research work is done on AMCs, the boron carbide particles are added as reinforcement with Aluminum cast alloy. Boron Carbide $\left(\mathrm{B}_{4} \mathrm{C}\right)$ has many attractive properties, such as low specific gravity, high hardness, high elastic modulus and neutron absorption, which help $\mathrm{B}_{4} \mathrm{C}$ to be widely used as cermets and armor materials. Composite plates of size $100 \mathrm{~mm} \times 100 \mathrm{~mm} \times 10 \mathrm{~mm}$ with 413 aluminum alloy as matrix material and $3 \%, 6 \%, 9 \%$ by weight of boron carbide, as reinforcement material were used as the work piece material. Brass wire with $0.25 \mathrm{~mm}$ diameter was used as the electrode, for conducting the WEDM experiments.

\section{FABRICATION OF COMPOSITES}

First of all, 413 alloys in the form of small ingots were placed in a crucible and melted in a resistance heated muffle furnace to the desired temperature of $850^{\circ} \mathrm{C}$. The crucible is covered with a flux in order to minimize the oxidation of molten metal and the melt was degassed by adding degasser. Then the aluminum alloy - boron carbide (3\%, 6\% and 9\%) composites were prepared by stir casting route. The boron carbide was preheated to $250^{\circ} \mathrm{C}$ for two hours in another furnace to remove the moisture. The size of the boron carbide is $63 \mu \mathrm{m}$. Then the boron carbide was added into the molten metal. The mixture was stirred continuously by using mechanical stirrer. The stirring time was maintained around 10 minutes at an impeller speed of $600 \mathrm{rpm}$. In the same time, small amount of flux (Potassium hexa fluro titanate) and degassing agents were added, to improve the quality of aluminum composite castings. The melt temperature was maintained at $800^{\circ} \mathrm{C}$ $850^{\circ} \mathrm{C}$, during the addition of the particles. Then, the melt was casted in a permanent die. The size of the die was 100x100x10 mm. Stir casting setup used in this work is shown in Figure 1.

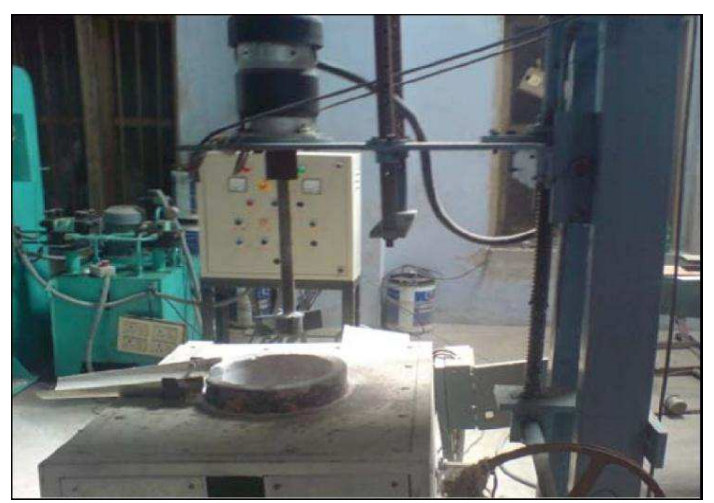

Figure 1: Stir Casting Setup

\section{WIRE EDM PROCESS}

In wire electric discharge machining, a wire is used as an electrode and de-ionized water as dielectric. Electrodes (wire and work piece) are connected to a pulsed DC supply. Heat generated due to sparking results in the melting of work piece and wire material, and sometimes part of the material may even vaporize like in conventional EDM. A constant gap between tool (wire) and work piece is maintained, with the help of a computer controlled, positioning system. This system is used, to cut through complicated contours especially in difficult-to-machine materials. This process gives a high degree of accuracy and a good surface finish. Photograph of CNC Wire EDM Machine used in this work is shown in figure 2. 


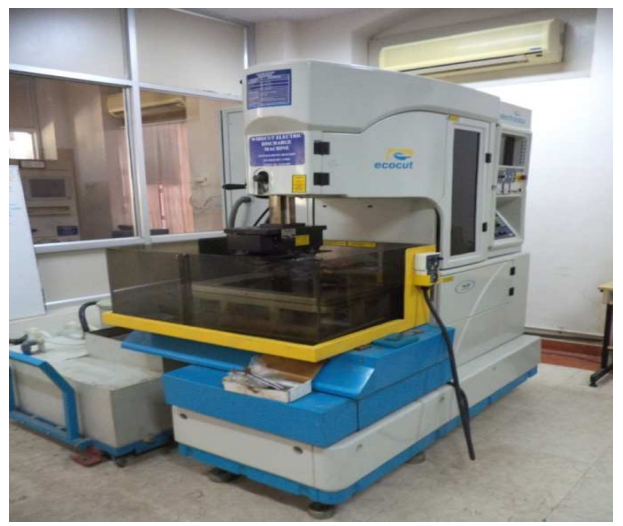

Figure 2: Photograph of CNC Wire EDM Machine

\section{TAGUCHI PARAMETRIC DESIGN}

Taguchi Techniques are statistical methods, developed by Genichi Taguchi, for improving the quality of manufactured goods, and more recently also applied to, engineering, biotechnology, marketing and advertising, by minimizing the effect of the cause of variation, without eliminating the cause. This method involves reducing the variation in a process through robust design of experiments. The overall objective of the method is to produce high quality product at low cost to the manufacturer. Typical experimental design methods are too complex and difficult to use and also it's required a large number of experiments when the factors are increased [15]. In this study, Taguchi method, a powerful tool for parameter design of performance characteristics, was used to determine optimal machining parameters for minimum SR and maximum MRR in WEDM. In Taguchi method, process parameters which influence the products are control factors, noise factor, signal factor and scaling factor [16]. The control factors are used to select the best conditions for stability in design of manufacturing process, whereas the noise factors denote all factors that cause variation. The experimental design proposed by Taguchi involves using orthogonal arrays to organize the parameters affecting the process and the levels at which they should be varied and to analyze the performance measure from the data to decide the optimal process parameters. This method uses a special design of orthogonal arrays to study the entire parameter space with minimum number of experiments only.

\section{RESULTS AND DISCUSSIONS}

In this study, five machining parameters were used as control factors and each parameter was designed to have three levels. According to the Taguchi quality design concept, a $\mathrm{L}_{27}$ orthogonal array was chosen and the experimental Results are shown in Table 1.

Table 1: Experimental Results

\begin{tabular}{|c|c|c|c|c|c|c|c|c|c|}
\hline $\begin{array}{l}\text { Ex. } \\
\text { No }\end{array}$ & $\begin{array}{c}\text { A } \\
\text { Gap Voltage } \\
\text { (V) }\end{array}$ & \begin{tabular}{|c|} 
B \\
Pulse On \\
Time $(\mu \mathrm{s})$ \\
\end{tabular} & $\begin{array}{c}\text { C } \\
\text { Pulse Off } \\
\text { Time }(\mu \mathrm{s})\end{array}$ & \begin{tabular}{|c|} 
D \\
$\begin{array}{c}\text { Wire Feed } \\
(\mathrm{m} / \mathrm{min})\end{array}$ \\
\end{tabular} & \begin{tabular}{|c|}
$\mathbf{E}$ \\
$\begin{array}{c}\text { Reinforcement } \\
(\mathrm{Wt} \%)\end{array}$ \\
\end{tabular} & $\begin{array}{c}\text { MRR } \\
\left(\mathrm{mm}^{3} /\right. \\
\mathrm{min})\end{array}$ & SR $(\mu \mathrm{m})$ & $\begin{array}{c}\text { S/N For } \\
\text { MRR }\end{array}$ & S/N For SR \\
\hline 1 & 30 & 2 & 2 & \begin{tabular}{|l|}
4 \\
\end{tabular} & \begin{tabular}{|c|}
3 \\
\end{tabular} & 29.023 & 3.52 & 29.25 & -10.93 \\
\hline 2 & 30 & 2 & 6 & 6 & 6 & 22.959 & 3.08 & 27.22 & -9.77 \\
\hline 3 & 30 & 2 & 10 & 8 & 9 & 17.882 & 3.66 & 25.05 & -11.27 \\
\hline 4 & 30 & 6 & 2 & 6 & 9 & 33.902 & 4.08 & 30.60 & -12.21 \\
\hline 5 & 30 & 6 & 6 & 8 & 3 & 29.7 & 3.26 & 29.46 & -10.26 \\
\hline 6 & 30 & 6 & 10 & 4 & 6 & 26.816 & 3.47 & 28.57 & -10.81 \\
\hline 7 & 30 & 10 & 2 & 8 & 6 & 45.686 & 3.92 & 33.20 & -11.87 \\
\hline 8 & 30 & 10 & 6 & 4 & 9 & 29.107 & 3.39 & 29.28 & -10.60 \\
\hline
\end{tabular}


Table 1: Contd.,

\begin{tabular}{|c|c|c|c|c|c|c|c|c|c|}
\multicolumn{10}{|c|}{ Table 1: Contd., } \\
\hline 9 & 30 & 10 & 10 & 6 & 3 & 30.387 & 2.99 & 29.65 & -9.51 \\
\hline 10 & 50 & 2 & 2 & 4 & 3 & 23.44 & 3.32 & 27.40 & -10.42 \\
\hline 11 & 50 & 2 & 6 & 6 & 6 & 16.316 & 3.2 & 24.25 & -10.10 \\
\hline 12 & 50 & 2 & 10 & 8 & 9 & 14.344 & 3.42 & 23.13 & -10.68 \\
\hline 13 & 50 & 6 & 2 & 6 & 9 & 25.893 & 3.47 & 28.26 & -10.81 \\
\hline 14 & 50 & 6 & 6 & 8 & 3 & 22.712 & 3.43 & 27.13 & -10.71 \\
\hline 15 & 50 & 6 & 10 & 4 & 6 & 19.675 & 3.24 & 25.88 & -10.21 \\
\hline 16 & 50 & 10 & 2 & 8 & 6 & 32.78 & 4.2 & 30.31 & -12.47 \\
\hline 17 & 50 & 10 & 6 & 4 & 9 & 23.314 & 3.96 & 27.35 & -11.95 \\
\hline 18 & 50 & 10 & 10 & 6 & 3 & 23.479 & 3.23 & 27.41 & -10.18 \\
\hline 19 & 70 & 2 & 2 & 4 & 3 & 13.7 & 3.33 & 22.73 & -10.45 \\
\hline 20 & 70 & 2 & 6 & 6 & 6 & 9.482 & 2.96 & 19.54 & -9.43 \\
\hline 21 & 70 & 2 & 10 & 8 & 9 & 8.775 & 3.93 & 18.86 & -11.89 \\
\hline 22 & 70 & 6 & 2 & 6 & 9 & 17.197 & 3.58 & 24.71 & -11.08 \\
\hline 23 & 70 & 6 & 6 & 8 & 3 & 13.413 & 3.01 & 22.55 & -9.57 \\
\hline 24 & 70 & 6 & 10 & 4 & 6 & 12.162 & 3.91 & 21.70 & -11.84 \\
\hline 25 & 70 & 10 & 2 & 8 & 6 & 18.78 & 3.91 & 25.47 & -11.84 \\
\hline 26 & 70 & 10 & 6 & 4 & 9 & 14.564 & 3.7 & 23.27 & -11.36 \\
\hline 27 & 70 & 10 & 10 & 6 & 3 & 13.56 & 3.16 & 22.65 & -9.99 \\
\hline
\end{tabular}

The experimental observations were presented and further transferred into signal to noise ratio (S/N ratio) as shown in table $1 . \mathrm{S} / \mathrm{N}$ is defined as the ratio of mean of the signal to the standard deviation of the noise. S/N ratio takes in to account the amount of variability in the response data and closeness of the average response to the target. The S/N ratio depends on the type of quality characteristics; namely lower the better, nominal is best, larger the better and fraction defectives. The $\mathrm{S} / \mathrm{N}$ ratio higher the better has selected for maximization problem for better machining performance (MRR). Inversely the characteristics that lower the better have selected for minimization problem say surface roughness values. The signal-to-noise $(\mathrm{S} / \mathrm{N})$ can be calculated as,

$$
\begin{aligned}
& \mathrm{S} / \mathrm{N} \text { ratio for MRR }=-10 \log _{10}\left(1 / \mathrm{y}^{2}\right) \\
& \mathrm{S} / \mathrm{N} \text { ratio for Surface finish }=-10 \log _{10}\left(\mathrm{y}^{2}\right)
\end{aligned}
$$

The analysis of experimental data was carried out using Minitab 15 software which is special tool for DOE application.

\section{ANALYSIS AND DISCUSSION OF RESULTS OF MRR}

The S/N ratio of the response characteristics for each variable at different levels were calculated from experimental data. In order to study the effect of process parameters on the MRR, experiments were conducted using $\mathrm{L}_{27}$ OA. Figure 3 shows that the MRR increases with increase in pulse on time and wire feed, and increases with decrease in gap voltage, pulse off time and reinforcement. This is because the discharge energy increases with the pulse on time leading to a higher material removal rate. As the pulse off time decreases, the number of discharges within a given period becomes more which leads to a higher MRR. With increase in gap voltage the average discharge gap gets widened resulting into a lower MRR. The effects of wire feed and reinforcement on MRR are not significant. It is also evident that MRR is minimum at first level of pulse on time and maximum at first level of pulse off time. 


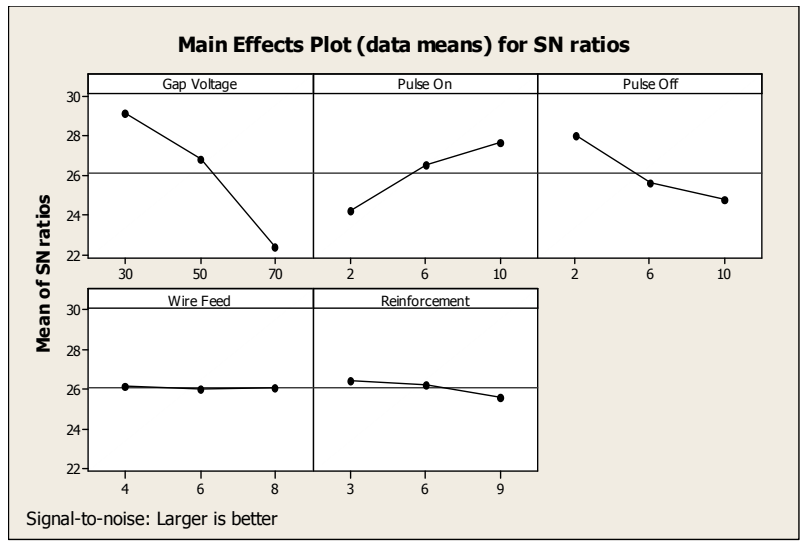

Figure 3: Response Graphs for MRR

\section{SELECTION OF OPTIMAL LEVELS FOR MRR}

The response Table 2 shows the average of each response characteristic ( $\mathrm{S} / \mathrm{N}$ data) for each level of each factor. The ranks indicate the relative importance of each factor to the response. The ranks and the delta values show that gap voltage has the greatest effect on MRR and is followed by pulse on time, pulse off time, reinforcement and wire feed in that order. As MRR is the 'higher the better' type quality characteristic, it can be seen from Figure 3 that the first level of gap voltage, third level of pulse on time, first level of pulse off time, first level of wire feed and first level of reinforcement provide maximum value of MRR in WEDM process.

Table 2: Response Table for MRR

\begin{tabular}{|c|c|c|c|c|c|}
\hline Level & Gap Voltage & Pulse On & Pulse Off & Wire Feed & Reinforcement \\
\hline 1 & $\mathbf{2 9 . 1 4}$ & 24.16 & $\mathbf{2 7 . 9 9}$ & $\mathbf{2 6 . 1 6}$ & $\mathbf{2 6 . 4 7}$ \\
\hline 2 & 26.79 & 26.54 & 25.56 & 26.03 & 26.24 \\
\hline 3 & 22.39 & $\mathbf{2 7 . 6 2}$ & 24.77 & 26.13 & 25.61 \\
\hline Delta & 6.75 & 3.46 & 3.22 & 0.13 & 0.86 \\
\hline Rank & 1 & 2 & 3 & 5 & 4 \\
\hline
\end{tabular}

The F-value from table at $5 \%$ significance level is $\mathrm{F}_{0.05,2,20}=3.49$. So, from ANOVA Table 3, we see that Gap Voltage, Pulse On time and Pulse off time are significant. The wire feed, percentage reinforcement, the interactions of Gap Voltage with Pulse On time, Gap Voltage with Pulse Off time, Gap Voltage with wire feed and Gap Voltage with percentage Reinforcement were pooled up into the error term.

Table 3: ANOVA for MRR

\begin{tabular}{|l|c|c|c|c|c|}
\hline Source of Variation & DOF & Sum of squares & Mean sum of squares & F $_{\mathbf{0}}$ & Contribution (\%) \\
\hline A & 2 & 211.69 & 105.845 & 369.44 & $65.19 \%$ \\
\hline B & 2 & 56.42 & 28.21 & 98.46 & $17.37 \%$ \\
\hline C & 2 & 50.90 & 25.45 & 88.83 & $15.67 \%$ \\
\hline Error(Pooled) & 20 & 5.73 & 0.2865 & & $1.77 \%$ \\
\hline Total & 26 & 324.74 & & & $100 \%$ \\
\hline
\end{tabular}

\section{CONFIRMATION EXPERIMENTS FOR MRR}

The optimum parameters are used for conducting the confirmation experiments and also for predicting the MRR. Experimental results are analyzed for identifying the optimum parameters. From Figure 3 and response Table 2 the factors at level A1, B3, C1, D1, E1 that is Gap Voltage $30 \mathrm{~V}$, Pulse on time $10 \mu \mathrm{s}$, Pulse off time $2 \mu \mathrm{s}$, Wire feed $4 \mathrm{~m} / \mathrm{min}$ and Reinforcement 3\% are the optimum parameters for obtaining maximum MRR. The predicted MRR is $38.149 \mathrm{~mm}^{3} / \mathrm{min}^{\mathrm{and}}$ 
experimental value of MRR is $38.600 \mathrm{~mm}^{3} / \mathrm{min}$.

\section{ANALYSIS AND DISCUSSION OF RESULTS OF SR}

The surface roughness for each parameter at levels 1, 2, and 3 for $\mathrm{S} / \mathrm{N}$ data are plotted in Figure 4 . It is seen from the Figure 4 the SR decreases with decrease in gap voltage, pulse on time, wire feed and reinforcement. It decreases with increase in pulse off time. This is because the discharge energy increases with the pulse on time and larger discharge energy produces a larger crater, causing a larger SR on the work piece. As the pulse off time increases, the number of discharges decreases which causes better surface accuracy and machining is stable. With increase in gap voltage the average discharge gap gets widened resulting into better surface accuracy. The effects of wire feed have less significance.

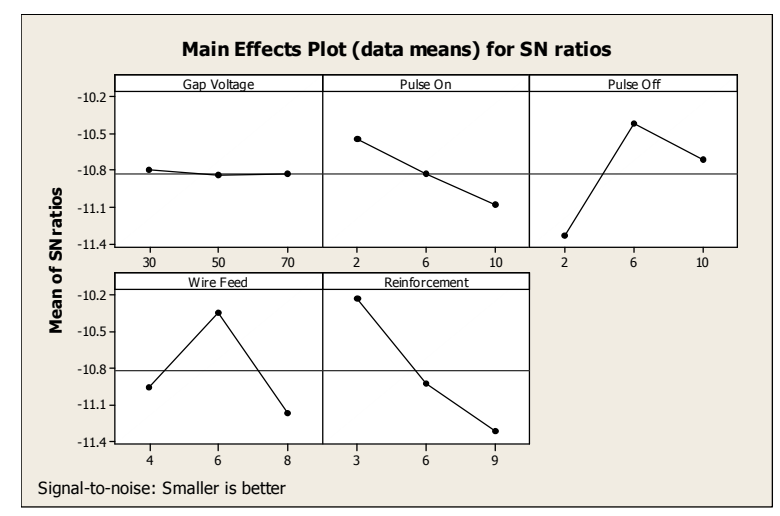

Figure 4: Response Graphs for SR

\section{SELECTION OF OPTIMAL LEVELS FOR SR}

The response Table 4 shows the average of each response characteristic ( $\mathrm{S} / \mathrm{N}$ data) for each level of each factor. Experimental results are analyzed for identifying the optimum parameters. As SR is the 'lower the better' type quality characteristic, it can be seen from Figure 4 that the first level of gap voltage, first level of pulse on time, second level of pulse off time and second level of wire feed and first level of reinforcement provide minimum SR in WEDM process.

Table 4: Response Table for SR

\begin{tabular}{|c|c|c|c|c|c|}
\hline Level & Gap voltage & Pulse on & Pulse off & Wire feed & Reinforcement \\
\hline 1 & $\mathbf{- 1 0 . 8 0}$ & $\mathbf{- 1 0 . 5 5}$ & -11.34 & -10.95 & $\mathbf{- 1 0 . 2 3}$ \\
\hline 2 & -10.84 & -10.83 & $\mathbf{- 1 0 . 4 2}$ & $\mathbf{- 1 0 . 3 4}$ & -10.93 \\
\hline 3 & -10.83 & -11.09 & -10.71 & -11.17 & -11.32 \\
\hline Delta & 0.04 & 0.54 & 0.92 & 0.83 & 1.09 \\
\hline Rank & 5 & 4 & 2 & 3 & 1 \\
\hline
\end{tabular}

In order to study the significance of the process variables towards SR, analysis of variance (ANOVA) was performed. The F-value from table at $5 \%$ significance level is $\mathrm{F}_{0.05,2,10}=4.10$ and $\mathrm{F}_{0.05,4,10}=3.48$ So, from ANOVA Table 5, we see that Pulse on time, Pulse off time, Wire Feed and Reinforcement were significant and also the interactions of Gap voltage with Pulse on time and Gap voltage with Pulse off time were significant The factors Gap voltage and interaction of Gap voltage with wire feed and Gap voltage with reinforcement were pooled up into the error term. 
Table 5: ANOVA for SR

\begin{tabular}{|l|c|c|c|c|c|}
\hline $\begin{array}{c}\text { Source of } \\
\text { Variation }\end{array}$ & DOF & Sum of squares & Mean sum of squares & $\mathbf{F}_{\mathbf{0}}$ & Contribution (\%) \\
\hline $\mathrm{B}$ & 2 & 1.307 & 0.6535 & 6.26 & $6.60 \%$ \\
\hline $\mathrm{C}$ & 2 & 4.010 & 2.005 & 19.20 & $20.25 \%$ \\
\hline $\mathrm{D}$ & 2 & 3.327 & 1.6635 & 15.93 & $16.80 \%$ \\
\hline $\mathrm{E}$ & 2 & 5.503 & 2.7515 & 26.36 & $27.78 \%$ \\
\hline $\mathrm{AB}$ & 4 & 1.651 & 0.41275 & 3.95 & $8.34 \%$ \\
\hline $\mathrm{AC}$ & 4 & 2.964 & 0.741 & 7.10 & $14.96 \%$ \\
\hline Error(Pooled) & 10 & 1.044 & 0.1044 & & $5.27 \%$ \\
\hline Total & $\mathbf{2 6}$ & $\mathbf{1 9 . 8 0 6}$ & & & $\mathbf{1 0 0 \%}$ \\
\hline
\end{tabular}

\section{CONFIRMATION EXPERIMENTS FOR SR}

The optimum parameters are used for conducting the confirmation experiments and also for predicting the SR. Experimental results are analyzed for identifying the optimum parameters. From Figure 4 and response Table 4 the factors at level A1, B1, C2, D2, E1 that is Gap Voltage $30 \mathrm{~V}$, Pulse on time $2 \mu \mathrm{s}$, Pulse off time $6 \mu \mathrm{s}$, Wire feed $6 \mathrm{~m} / \mathrm{min}$ and Reinforcement 3\% are the optimum parameters for obtaining minimum SR. The predicted SR is $2.78 \mu \mathrm{m}$ and experimental value of $\mathrm{SR}$ is $2.75 \mu \mathrm{m}$.

\section{CONCLUSIONS}

This paper has presented an investigation on the optimization and the effect of machining parameters on the MRR and the surface roughness in WEDM operations. An optimum parameter combination for the maximum MRR and minimum SR was obtained by using the signal-to-noise $(\mathrm{S} / \mathrm{N})$ ratio. The confirmation tests indicated that it is possible to decrease the surface roughness and increase material removal rate significantly by using the proposed statistical technique. The optimal levels of machining parameters of WEDM process were at level A1, B3, C1, D1, E1 gives the maximum MRR. The optimal levels of machining parameters of WEDM process were at level A1, B1, C2, D2, E1 gives the better SR.

\section{REFERENCES}

1. W. Bunk, P. Esslinger, H. Keller, Aerospace materials: trends and potential, Materials and Processing $Ð$ Move into the 90's, Elsevier, Amsterdam, 1989, pp. 327+341.

2. M. Kathiresan and T. Sornakumar "EDM Studies on Aluminum Alloy-Silicon Carbide Composites Developed by Vortex Technique and Pressure Die Casting” Journal of Minerals \& Materials Characterization \& Engineering, Vol. 9, No.1, pp.79$88,2010$.

3. S. Durantea"*, G. Rutellib, F. Rabezzana, Aluminum-based MMC machining with diamond-coated cutting tools, Surface and Coatings Technology 94-95 (1997) 632-640.

4. D. Brazil, J. manghan, D,K Aspinwall, E-G Ng, Wear characterization of various diamond tooling when single point turning a particle reainforced metal matrix composite, in proceedings of the IMC-14, conference, Duplin Ireland 1997,pp143-152.

5. Poon, T. C. Lee, Electrical discharge machining of particulate metalmatrix composites, in: Proceedings of the ASME 1993

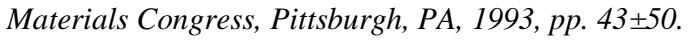

6. Che Chung Wang \& Biing Hwa Yan 2000, „Blind-hole drilling of Al2O3/6061 Al composite using rotary electro-discharge machining", Journal of Materials Processing Technology, vol. 102, pp. 90-102. 
7. Sivaprakasam, P, Hariharan, P\& Gowri, S 2013, „Optimization of micro wire electric discharge machining process of aluminium matrix composites (A413/ B4C): A response surface approach", Materials and Manufacturing Processes, vol. 28, pp. 1340-1347.

8. J. Udaya Prakash, J. Milton Peter, and T. V. Moorthy. "Optimization of Wire EDM Process Parameters of Aluminium Alloy/Flyash/Boron Carbide Hybrid Composites." International Review of Mechanical Engineering vol 6 no.3 (2012) pp 449455.

9. J. Udaya Prakash, T. V. Moorthy, and J. Milton Peter. "Experimental Investigations on Machinability of Aluminium Alloy (A413)/Flyash/B 4 C Hybrid Composites using Wire EDM." Procedia Engineering 64 (2013): 1344-1353.

10. P. Arivazhagan, A. Rajadurai, Proc. Int. Conf. on Advances in Mechanical and Industrial Engineering, 6-8 February, 1997, Roorkee, India, pp.709-716.

11. Jyoshna Joshi \& Onkar Sonare, Optimisation of Wire EDM Process Parameters on D3 Tool Steel using Principal Component Analysis, International Journal of Mechanical and Production Engineering Research and Development (IJMPERD), Volume 7, Issue 2, March - April 2013, pp. 31-40

12. Le Roux, M. L. H. Wise, D. K. Aspinwall, Electric discharge machining of an aluminum alloy silicon carbide reinforced metal matrix composite, in: Proceedings of the 30th MATADOR Conference, Manchester, 1993, pp. 247-254.

13. M. Rozenek, K. èubkowski, J. Kozak, L. DaÎlbrowski, Geometrical structure of surface machined by WEDM, in: Proceedings of the Conference on In-uence of Manufacturing Processes on State of Surface Layer Đ SL'96, GorzoÂw Wlkp (in Polish).

14. De Silva, J. Ranke, Electrical discharge machining of metal matrix composites, in: Proceedings of the International Symposium for Electromachining ISEM'11, Lausanne, 1995, pp. 75-84.

15. M. Ramulu, M. Taya, EDM machinability of SiCw/Al composites, J. Mater. Sci. 24 (1989) 1103-1108.

16. W. H. Yang, Y. S. Tarng, Design optimization of cutting parameters for turning operations based on the Taguchi method, J. Mater. Process. Technol. 84 (1998) 122-129.

17. T. R. Lin, Optimization technique for face milling stainless steel with multiple performance characteristics, Int. J. Adv. Manuf. Technol. 19 (2002) 330-335. 